\title{
Life as a Cosmic Phenomenon: The Socio-Economic Control of a Scientific Paradigm
}

\section{N Chandra Wickramasinghe ${ }^{1,3}$ and Gensuke Tokoro ${ }^{2,3}$}

${ }^{1}$ Buckingham Centre for Astrobiology; University of Buckingham, Buckingham, UK

${ }^{2}$ Hitotsubashi University, Institute of Innovation Research, Tokyo, Japan

${ }^{3}$ Institute for the Study of Panspermia and Astroeconomics, Gifu, Japan

\begin{abstract}
A major paradigm shift with potentially profound implications has been taking place over the past 3 decades at a rapidly accelerating pace. The Copernican revolution of half a millennium ago is now being extended to place humanity on the Earth in its correct cosmic perspective - an assembly of cosmically derived viral genes, no more, no less, pieced together over 4 billion years of geological history against the processes of Darwinian natural selection. The evidence for our cosmic ancestry has now grown to the point that to deny it is a process fraught with imminent danger. We discuss the weight of modern scientific evidence from diverse sources, the history of development of the relevant ideas, and the socio-economic and historical forces that are responsible for dictating the pace of change.
\end{abstract}

Keywords: Panspermia; Cosmic origins of life; Economics; History of science

\section{Introduction}

"Falsehood and delusion are allowed in no case whatever: but, as in the exercise of all the virtues, there is an economy of truth. It is a sort of temperance, by which a man speaks truth with measure that he may speak it the longer...."- Edmund Burke, 1849: The works of Edmund Burke, with a memoir 2. Harper \& Brothers. p. 248.

Economy of Truth is a principle of limitation often used by politicians whenever the Whole Truth is deemed strategically unwise. We show in this article that the same principle is used in science as a mode of controlling the flow of information, and the mechanism of control involves the collective and often covert decisions of large and diffuse societal groups.

In modern times the involvement of the State or of large organisations in the conduct of science has become necessary to varying degrees. This is due mainly to the requirement of funds to set up laboratories, which are often expensive and beyond the reach of individual scientists. Moreover, the so-called "big" projects require large teams of scientists using expensive equipment. So, organisation and central control becomes imperative. Examples of ongoing big projects include the space exploration of planets by NASA and other similar space agencies, the Hadron Collider operated by CERN, and major genome sequencing projects in several countries - to name but a few.

In its earliest beginnings science arose as the solitary pursuit of individual philosophers whose ideas were often opposed to the status quo. The pre-Socratic philosopher Anaxoragas in the $5^{\text {th }}$ century BC declared that the Sun was a red hot stone and the Moon was made of earth, and for his heresy he was banished from Athens. State-control of science is therefore no new thing. Examples are to be found scattered throughout history - extending from the time of classical Greece, through the long saga of the Ptolemaic epicycles in the Middle Ages, the control of science by the Papacy, and to some degree, stretching through into modern times. Although academic freedom is enshrined in most University statutes today, its implementation often leaves much to be desired.

There are many aspects of the conduct of $21^{\text {st }}$ century science that are similar to the behaviour of a totalitarian state. A totalitarian regime in politics sets out a rigid framework of rules to govern society, and a system of law for punishing those who disobeyed. Transgressions being met with severe penalties implied that there was always a firm motive for citizens to conform. Communist regimes, such as existed in the Soviet Union in the $20^{\text {th }}$ century, fit well into this general pattern. Marxist-Leninist philosophy was based on denouncing the perceived evils of capitalism, and its implementation involved a great deal of state control of property and resources, as well as, unfortunately, severe restrictions in freedom of speech.

Whilst in the spheres of politics and economics such state control may have a justification as a prerequisite for firm government, a similar control extending to other areas of creativity including art, music and science, is less desirable, and may act in a way that impedes progress. The justification of eugenics in Nazi Germany with its grotesque and inhumane consequences and the enforcement of obscurantist biological theories in the Soviet Union, provide examples of such conduct. Biology under Marxism also vigorously defended the principle of spontaneous generation despite the fact that this principle was essentially disproved by the experimental work of Louis Pasteur in the 1860's.

Ideas of the Russian Biologist Alexadandir Oparin that led to the theory of the origin of life in a primordial soup were undoubtedly inspired by the tenets of dialectical materialism. Oparin and the Soviet scientists drew their inspiration from the German Philosopher Freidrich Engels who had proposed that new qualities of "being" arose at each new stage of organic evolution. Engels noted that higher levels of existence resulted from lower levels, and this progression was deemed part of the natural order of things. The primordial soup paradigm of the origin of life derived from this philosophy still remains the reigning

*Corresponding author: Wickramasinghe NC, Buckingham Centre for Astrobiology, University of Buckingham, Buckingham, UK, Tel: 44-777-83892432, E-mail: NCWick@gmail.com

Received June 09, 2014; Accepted June 25, 2014; Published June 27, 2014

Citation: N Chandra Wickramasinghe, Tokoro G (2014) Life as a Cosmic Phenomenon: The Socio-Economic Control of a Scientific Paradigm. Astrobiol Outreach 2:113. doi: 10.4172/2332-2519.1000113

Copyright: (c) $2014 \mathrm{~N}$ Chandra Wickramasinghe et al. This is an open-access article distributed under the terms of the Creative Commons Attribution License, which permits unrestricted use, distribution, and reproduction in any medium, provided the original author and source are credited. 
dogma in science although its political and philosophical antecedents are now largely forgotten.

A more sinister development in the Soviet Union was the political control exerted by Trofim Lysenko in relation to ideas in genetics and agriculture. Lysenko built upon outmoded ideas of Lamarck concerning the heritability of acquired characteristics, and in so doing departed from the proven ideas of Mendelian inheritance. Lysenkoism dominated Soviet biology from the late 1920's for a full three decades. It was embraced by the authorities and was considered well-suited to the Marxist-Leninist ideals of the State.

As we already mentioned, science in the earliest days arose from the initiative of a few, often rebellious, individuals who did not require support or sponsorship from the State. Aristarchus of Samos (310230BC) and Hipparcus of Niceae (190-120BC) who estimated the sizes of the Earth, Moon, Sun and the distances of stars by methods of parallax, did not need any expensive equipment. Their work could not therefore have been stopped or prevented by State intervention, if the state happened to be hostile to the outcome.

\section{Transition to Modern Times}

Modern science has taken on a totally different complexion, where progress depends crucially on expensive equipment, large teams of workers, and the support, direct or indirect, of large organisations sponsored by the State. If ideas ran counter to those of an influential majority, or a powerful establishment, progress will be severely hampered. This is true both in a capitalist system as well as under communism such as prevailed in the old Soviet Union. In either case the control of new ideas is what one would expect within a totalitarian political system. Dissent from a majority position in science is quickly and effectively quelled by starvation of funds or the chastisement of those attempting to promote contrary views.

If all this is true, how, one might ask, is scientific progress still taking place, seemingly at an astounding pace? To answer this question it is useful to divide science into several types. The type of empirical/ predictive science that informs us how matter - living or non-living - behaves is the kind of science that we routinely learn at school and University. The mechanics of Newton, atomic and nuclear physics, the well-attested properties of matter and radiation, do not offer themselves as subjects of political dispute of any kind. It is upon this kind of science

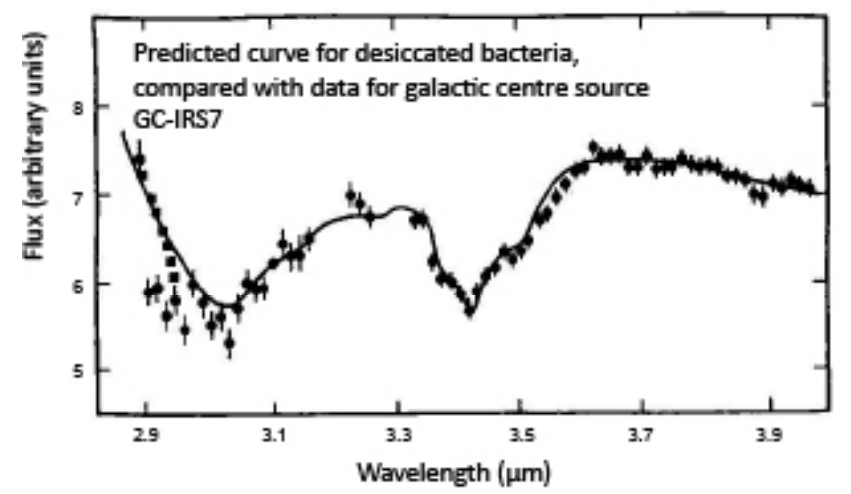

Figure 1a: The first prediction of the bacterial model of interstellar dust compared with the observations of the Galactic Centre infrared source GCIRS7. The agreement implied that 30 percent of the carbon in interstellar space is tied up in the form of dust that cannot be spectroscopically distinguished from freeze dried bacteria. that the entire structure of modern technology depends. Although biology at a molecular level - e.g. DNA, sequencing - comes in the same category, the bigger organisational and inferential structures of biology - e.g. theories of the origin and evolution of life - lend themselves to manipulation, by political and scientific authorities.

\section{Case Study of Conflict}

\section{Spectroscopic evidence}

When Fred Hoyle and one of the present authors began to investigate the complex organic nature of interstellar dust in the 1970's the strongly entrenched biological paradigm was the Oparin-Haldane model of an origin of life in a primordial soup of organics, a system that was firmly rooted on the Earth [1-3]. With the very much vaster quantities of organic molecules and dust in the form of organic polymers that were discovered in the Universe at large, a cosmic primordial soup and an astronomical origin of life began to suggest itself as being far more likely [4]. We explored this idea in a series of monographs and a long series of scientific papers in journals including Nature [5-8].

The Editor of Nature at the time, Sir John Maddox, was enlightened enough to publish our articles with a view to encourage debate [8]. But to our disappointment, these letters and articles did not stimulate the much required debate. Rather there was a mysterious tendency to ignore them, almost to pretend they did not exist!

Attempts to influence various scientific bodies to invest in the idea of cosmic life, and to carry out certain explicit tests also ended in failure. In 1979 Hoyle and one of us attempted, via the good offices of NCW's brother Dayal Wickramasinghe, to secure time on the AngloAustralian Telescope to test a prediction of organic dust in the direction of the centre of our galaxy.

Some months earlier we had measured the infrared spectra of bacteria under space conditions and predicted an astronomical test to verify our theory [9-11]. This attempt to carry out such a test met with firm rejection by the Anglo-Australian Telescope Board. It was deemed that the same telescope that Fred Hoyle himself had played a big role in setting up [12], could not "afford" a few minutes of its observing time to test his theory of the cosmic origins of life. Applications were also made to the UK's Science Research Council for support of this work on the organic composition of interstellar dust, and these too were refused.

As it turned out, however, the relevant telescope observations for which support had been sought for in 1979 and refused were eventually made in 1982 and the predictions of a bacterial dust model were overwhelmingly verified [13]. This is shown in Figure 1a. A whole range of astronomical observations of a similar kind all point to the widespread existence of cosmic dust with a composition resembling that of living material [14]. The prevailing reluctance, however, is to admit that that these organics are really the products of biology. The fashionable point of view nowadays is to assert without any proof that organic chemistry is occurring everywhere, and the resulting chemicals happen perchance to match exactly the spectral behaviour of desiccated bacteria! Furthermore it is maintained against all the odds that terrestrial life originated in a geological instant in situ on the Earth, after organic molecules from space came to be delivered possibly by the agency of comets (see Case Study of Conflict below).

The theory that Hoyle and one of the authors advanced through the 1970 's and 1980's was that the origin of life was a unique cosmological (or galactic) event, and that its panspermic transfer as freeze-dried microorganisms via comets is inevitable $[11,15]$. The prediction of the 
Citation: N Chandra Wickramasinghe, Tokoro G (2014) Life as a Cosmic Phenomenon: The Socio-Economic Control of a Scientific Paradigm. Astrobiol Outreach 2:113. doi: $10.4172 / 2332-2519.1000113$

Page 3 of 7

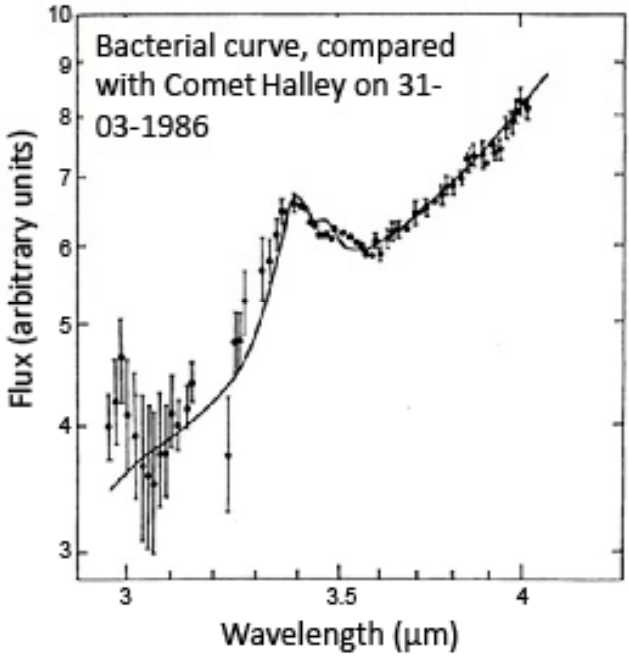

Figure 1b: The predicted thermal emission behaviour for dust from Comet Halley for a bacterial dust model, compared with observations.
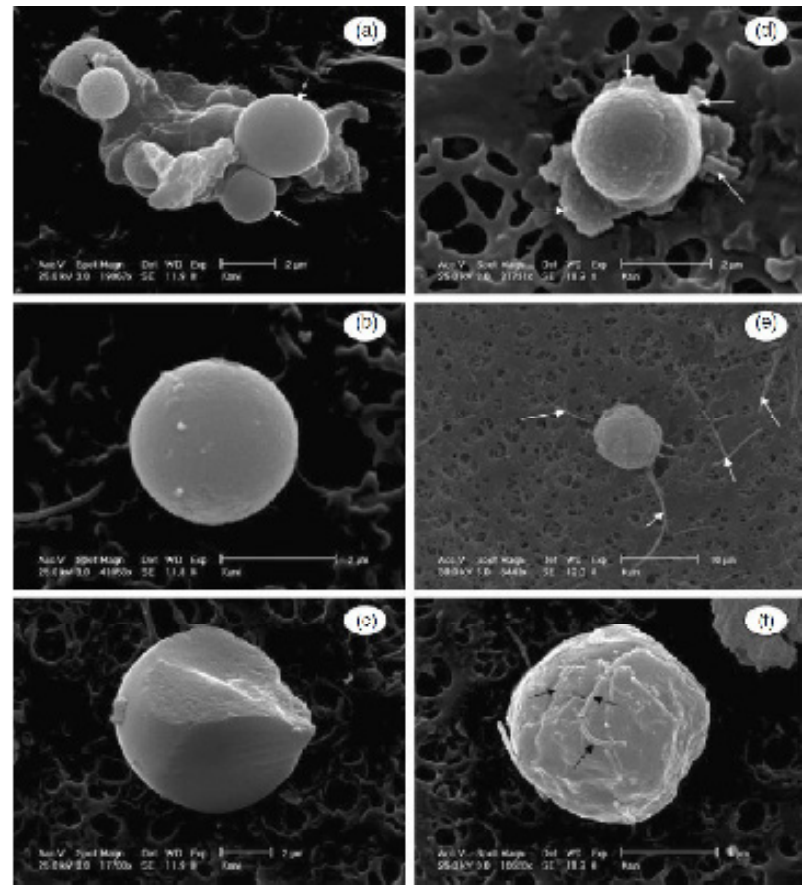

Figure 2a: Shows putative biological structures in the 2001 collection from the stratosphere.

biological character of cometary dust came to be vindicated by the first space probe investigations of a comet - Comet Halley - in 1986.

The startling correspondence between our predicted thermal behaviour of evaporated dust and the bacterial grain model is shown in Figure 1b. Figures 1a and $1 \mathrm{~b}$ provide examples of predictions of the biological dust model that were made before observations were made, and where dramatic correspondences were later emerge. The normal methodology of science would involve giving such a model a decisive 'thumbs up' - at any rate until later falsifying evidence may have come to light.

\section{Growing support for panspermia}

It was as recent as in 1995 that astronomers began to find definite evidence that other stars outside our solar system have planets orbiting them [16]. Today thousands of "exoplanets" orbiting distant stars have been detected [17]. Estimates of habitable planets, based on new data from NASA's Kepler mission, have given numbers in excess of 100 billion in our galaxy alone. This means that the mean distance between habitable planets is only a few light years, a distance that is easily bridged by exchanges of comets and other planetary bodies that can act as agencies for the transfer life. So cometary panspermia of the type first proposed by Hoyle and one of the present authors is essentially unavoidable (Hoyle and Wickramasinghe, [6]). The fact that the oldest evidence of life on Earth is present in sediments that were laid down some 4 billion years ago during a period of intense cometary bombardment (Hadean epoch) is a strong indication that comets brought life to our planet [18].

\section{Balloon experiments to collect comet dust}

Undaunted by all the social impediments and political obstacles we faced, Hoyle and Wickramasinghe continued to amass data from a wide range of disciplines, all of which unerringly supported our thesis of life being a cosmic phenomenon [19-21]. We persevered also by continuing to devise and propose tests and predictions in a variety of different directions. One prediction involved the retrieval of pristine cometary material from high in the Earth's stratosphere (well above the tropopause) before it settled to lower altitudes and became mixed with contaminants in the terrestrial biosphere. We made requests to UK space and aerospace agencies to seek support for this vitally important project, but all our pleadings once again fell on deaf years.

Finally the Indian Space Research Organisation agreed to carry out our proposed experiments. In January 2001, in collaboration with a group of Indian scientists led by J.V. Narlikar of the Inter-Universities Centre for Astronomy and Astrophysics in Pune, we sent balloon-borne devices (cryosamplers) to a height of $41 \mathrm{~km}$ to collect stratospheric air and aerosols asceptically. Positive results that were obtained indicated that our prediction of a continuing ingress of biomaterial from comets was dramatically verified [21]. A similar experiment was repeated by ISRO in 2009 [22] and 3 new microorganisms were discovered, including one named in honour of Fred Hoyle as Janibacter hoylei. Figure 2a shows putative biological entities discovered in stratospheric samples by electron microscopy; and the left panel of Figure $2 \mathrm{~b}$ shows a clump of putative cocci and a bacillus. The right panel of Figure $2 b$ shows evidence of viable microorganisms which did not prove to be culturable.
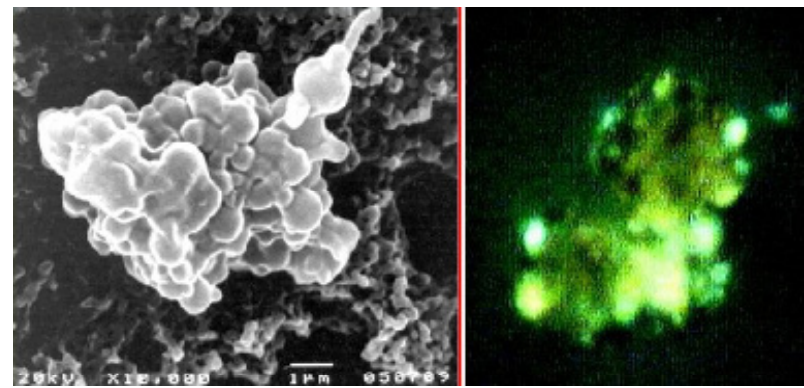

Figure 2b: Left: a clump of carbonacesous particles resembling cocci and a bacillus Right: A clump of viable but non-culturable bacteria fluorescing under the application of a carbocyanine dye which tests for electric potential across cell walls. 


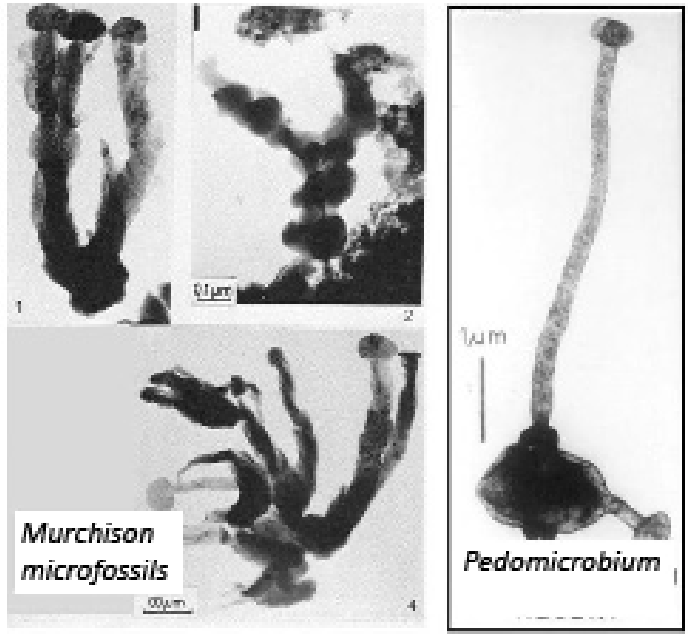

Figure 3: Hans Pflug's microbial fossils in the Murchison meteorite compared with a recent terrestrial microorganism - Pedomicrobium.

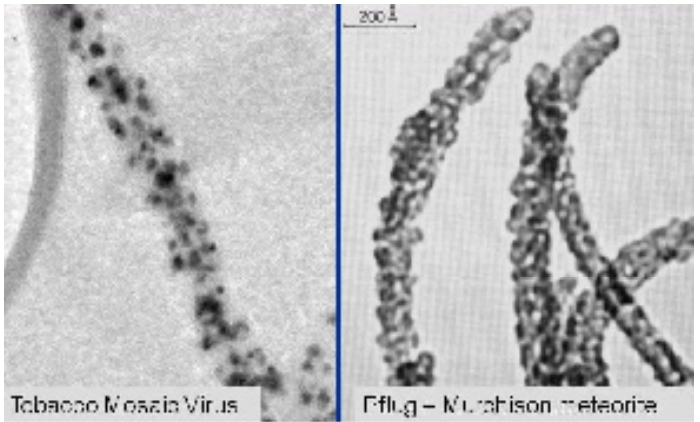

Figure 4: Hans Pflug's viral fossils in the Murchison meteorite compared with Tobacco mosaic virus.

The genetic similarities of the new stratospheric bacteria to existing terrestrial genera have been cited as an argument to discount their possible space origin. However, in our view, terrestrial bacterial genera all have a space origin, so homologies of the type found are to be expected and do indeed corroborate a space origin of all bacteria on Earth $[7,23]$. In order to take the matter further, and hopefully reach a decisive conclusion, further tests of the collected microbial samples would be desirable. One such test involves the deployment of a rather rare laboratory resource - a Nanosims machine. This will determine the isotopic composition of carbon, oxygen and other constituent elements within the individual bacterial cells, and if the composition turns out to be non-terrestrial, it is QED! The tight control of the relevant experimental resources worldwide has so far prevented us from gaining access to this equipment. The sceptic is thus left in a seemingly comfortable position to assert, if he so wished, that what we have found in our balloon samples in 2001 and 2009 were terrestrial contaminants. This is just one instance of totalitarian control of science that is hindering progress and cannot be easily overcome.

\section{Viruses in our genes}

A correct theory in science has repercussions extending in many different directions - some often unexpected. The idea of cosmic life is no exception in this regard. Long before the human genome came to be sequenced, Hoyle and one of the present authors argued that viral infections leading to pandemics throughout history must also have a cosmic origin, and that these infections have a positive role in the evolution of terrestrial life [7]. It is through such infective processes that new genes for evolution are derived gratis from the cosmos, if not for which biological evolution must grind to a halt. If viruses were exclusively bad or deleterious for higher life it would be most remarkable that higher life forms, in the course of their long evolution, have not developed a mechanism for preventing the ingress of devastating viruses. Logically, the very much larger information content of our own DNA would surely have been able to outwit and combat the trivial information content of a viral genome. We argued in 1982 that the fact that this has not happened must indicate that the process of viral ingress is somehow necessary for evolution [7].

The decoding of the human genome after 2001 has led to many revolutions in modern biology. One surprise to emerge was to discover that there were far fewer genes coding for proteins than had hitherto been thought to exist - possibly less than 25,000. Another surprise was that a large proportion of our DNA is actually comprised of viral sequences, consistent with a long succession of past pandemics. Each such pandemic led, it would seem, to a near culling of our entire evolving ancestral line. Only a very small surviving immune breeding group survived at each stage to transmit the legacy of viral genes through to the present time [14].

\section{History of microfossils in meteorites}

From the early 1960's evidence of extraterrestrial lifeforms - albeit in fossilised form - had been available and became subject to vigorous debate [24]. From the 1980's onwards the evidence of microfossils was so strong as to generate exceedingly vicious opposition in the scientific community. Hans D. Pflug studied carbonaceous meteorites and found striking evidence of microbial fossils - bacteria and viruses deeply embedded within them. Morphologically the identification with well-known terrestrial forms was beyond dispute, and issues of contamination that plagued earlier work were adequately dealt with by use of improved techniques that left very little room for argument [25]. Figures 3 and 4 show instances of organic microstructures in the Murchison meteorite that fell near the town of Murchison in Australia in 1969. These structures can be easily indentified with well-known bacterial and viral entities. If this data is accepted at face value, then the paradigm shift from "Earth-bound life" to "cosmic life" would be instantly achieved. This, however, was not to be.

It came as no surprise that the new evidence of extraterrestrial life was once again either rejected or ignored by scientific orthodoxy, and so the data from microbial fossils drifted once again into obscurity. A revival of interest in this matter followed a long series of investigations by R.B. Hoover, but this later work was also peremptorily dismissed as being either artifacts, or contaminants $[26,27]$. But the real world of science - the Universe - does not yield abjectly to the strictures of authority, no matter how powerful its sources might be.

\section{Sri lankan meteorite}

It is against this backdrop that a witnessed fireball event, followed by a meteorite fall in central Sri Lanka on 29 December 2012, came to be studied. When samples of the meteorite were examined using an electron microscope there was little room for disputing the existence of fossilised microbial structures, including diatoms, the characteristic morphologies and microstructures of which were diagnostic of their biological provenance $[14,28,29]$ Figure 5. 


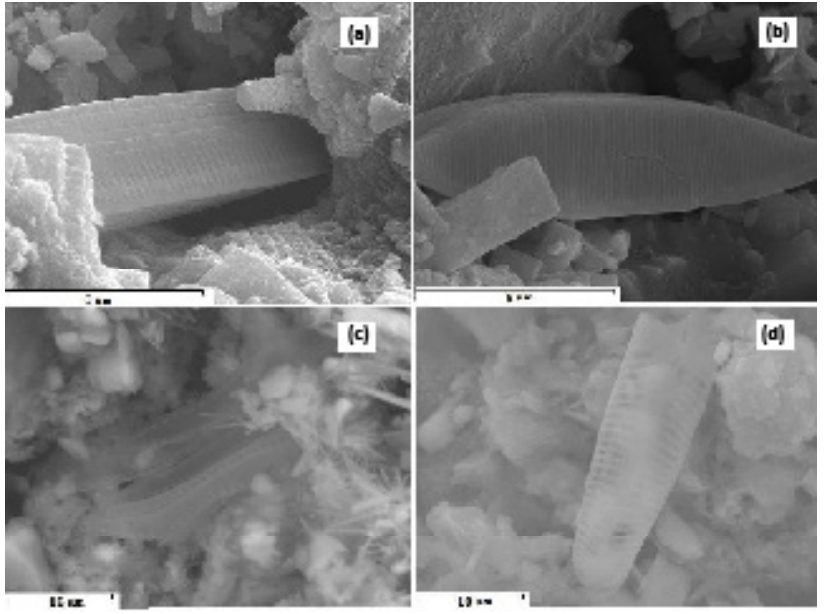

Figure 5: Diatom frustules deeply embedded in the Sri Lankan (Polonnaruwa) meteorite that fell on 29 December 2012.

The voices of dissent that have been uttered, mostly off-stage, are to the effect that the rocks containing these microfossils cannot be accepted as meteorites. The porous, fluffy structure of the stones does not readily fit with any well-established meteorite class, and so also is their high silica content. However, the undisputed connection with a fireball, anecdotes of hands burnt on touching the stones, evidence of distinct fusion crusts, and the timing of the event at the end of the December Taurids, all corroborate a meteorite identification.

Most significant, however, is the evidence derived from within the stones themselves. They possess isotopic, chemical and mineralogic characteristics all of which are inconsistent with a terrestrial origin. The distribution of stable oxygen isotopes has been shown to be clearly consistent with a meteoritic origin, as also the presence of impact mineral phases (e.g. Maskelenite) and a high abundance of the element iridium (Wallis et al, 2013). High iridium content in terrestrial sediments (e.g. the $\mathrm{K} / \mathrm{T}$ boundary) is interpreted without dissent as being due to cometary material. It would seem strange that this has not been accepted as a valid criterion in the case of the Sri Lankan Polonnaruwa meteorite. From the physical and chemical evidence alone there cannot be any doubt that these stones are indeed meteorites - albeit of a new class - that contains unequivocal evidence of biology. Moreover, such life as exists in the meteorite appears to be closely related to well-recognised species of diatoms that exist on the Earth.

\section{Stratospheric meteoroids}

The existence of microbiota in meteorites, in particular within cometary micrometeorides that form part of a meteor stream, was recently established by a team led by Milton Wainwright (Wainwright et al., [30-33]). A balloon-borne device to collect impacting cometary micrometeoroids was flown to a height of $27 \mathrm{~km}$ in the stratosphere in June 2013 during the Perseid meteor shower. The device involved an assembly of electron microscope stubs that were exposed to the stratosphere at the peak of a balloon flight for 17 minutes and thereafter securely sealed and parachuted back to ground. The exposed stubs, once they were recovered, were examined under an electron microscope. Clear evidence was found of infalling microorganisms, some of which actually cratered the recipient stubs, as shown for instance in Figure 6. Slow-drifting of organic particles lofted from the ground was ruled out on various grounds, not least the fact that the craters on the stubs implied downward descent and impact at high speed.

The image shown on the left of Figure 6a. is of a spherical cell possessing a thin titanium shell that was micro manipulated out of a crater pit, with organic ooze visibly emerging in the process. Several other biological structures, including the diatom frustules shown in right hand box in Figure 6, were also discovered on the stubs. All these were falling downwards on to the stubs at high speed and must therefore have a Cometary origin.

\section{The Verdict}

If a jury comprised of 12 impartial men and women were presented with the full range of evidence on the existence of extraterrestrial life, and the cosmic origins of life, there is scarcely any doubt that the verdict will be positive. So overwhelming is the totality of the evidence we have discussed. Ingress of extraterrestrial life to the Earth would appear to have been established beyond a shadow of doubt. The fact that this conclusion is not widely known or publicised is in the authors' view entirely a function of state control of scientific paradigms, of a kind reminiscent of the behaviour of totalitarian political regimes. Refusal to conform with the strictures of authority is met with serious consequences that are particularly damaging for young scientists at the start of their careers in science. For them the award of grants to support their work, approbation by peers, or even their very livelihood is threatened. Under such repressive constraints progress toward any form of objective truth is virtually impossible.

\section{Economy of Truth}

To the general public, whose level of science education is limited, the difference between organic chemicals delivered to Earth by comets and the transport of fully-fledged living cells may be too subtle, and might easily go unnoticed. The evidence of molecules that could serve as building blocks of life delivered by comets and meteorites has now developed to the point of near certainty and is widely reported in science journals and in the general news media as well [33]. Most people tend to misread such reports as implying a paradigm shift to extraterrestrial life which is, of course, still being kept at bay.

In this connection it is of interest to recall that some 35 years ago

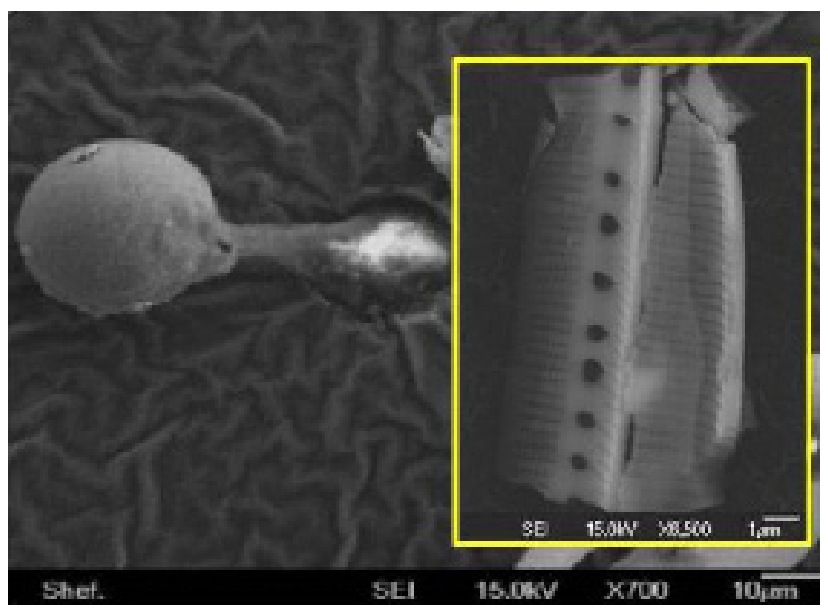

Figure 6: Left: A spherical biological cell possessing a thin titanium shell that was micro manipulated out of a crater pit, with organic ooze visibly emerging in the process. Right: diatom frustule that landed at speed from above. 
the assertion of biochemicals in interstellar dust and their transport to Earth via comets sparked intense controversy. Hoyle and one of the present authors (Hoyle and Wickramasinghe, [4]) wrote in their book Lifecloud thus:

"The point of view we have developed so far implies that the essential biochemical requirements of life exist in very large quantities within the dense interstellar clouds of gas, the so called molecular clouds. This material became deposited within the solar system, first in comet-type bodies, and then in the collisions of such bodies with the Earth. We might think of the Earth as having become infected with life-forming materials......." Lifecloud, p.157.

Such statements were seized upon by many critics at the time. For instance, W.W. Duley and D.A. Williams wrote thus in Nature: "....We concludes that no spectroscopic evidence exists to support the contention that much of the interstellar dust consists of organic materials......." Nature, 277, 4 January 1979.

It is however this weakest form of panspermia proposed in Lifecloud that is now wholeheartedly embraced by science journals, and serves as a deliberately chosen device to keep the full force of evidence for ingress of extraterrestrial life from coming to the public's notice.

\section{Socio-economic Constraints}

A paradigm shift of the kind we have discussed in this article may be stalled for seemingly rational reasons based on either prudence or pragmatism:

a) The proposed paradigm shift from Earth-centred life to cosmiccentred life might be perceived as a threat to national security. People may become so scared and emotionally unsettled that even the enforcement of law and order might pose a problem.

b) To admit that we have supported a wrong paradigm may have economic repercussions in regard to the many large funding commitments already in place for exploring ideas based on a wrong premise.

c) An inevitable demand that would follow for re-orientation of existing space programmes would have serious fiscal implications that would need to be kept in mind.

d) It would have to be deemed prudent to monitor the stratosphere for potentially lethal incoming pathogens, and such a worldwide programme would require large budgets as well as new strategies in world health economics.

None of the above reasons would be good enough to halt the entry of a new paradigm which is long overdue. As in the sphere of politics change ultimately comes about as a result of social opposition and protest, and public opinion eventually triumphs. From the earliest times primitive man appears to have had an innate perception of a connection between life and some major aspect of the Universe. The fact that most primitive gods and goddesses being invariably placed in the skies was itself an expression of this link. With the dawn of civilization more explicit expressions of a belief in alien life gradually came to the fore. Giordino Bruno's famous assertions on alien life that led to his death in 1600 are well known, and similar assertions have punctuated history. The modern interest in aliens expressed in science fiction can generally be interpreted as an implicit acknowledgement of alien life, and furthermore of our own intimate connection with it.

It is a curious fact that whilst SiFi movies portraying alien life make box office hits, the vast body technical data on alien life such as we have accumulated in recent years, and discussed in this article, are scarcely known to the public at large. This is not due to any weakness or inadequacy of the evidence itself, but due to the fact that prominent science journals that enjoy media exposure deliberately act as censors of "unacceptable" science. In such a situation no discoveries get to be published except those that are considered pleasing to an academic orthodoxy. We thus have a situation of total and absolute control of information in science and this is surely to be regretted.

\section{Conclusion}

In conclusion I wish to refer to a remarkable statement issued in 2013 in connection with the World Economic Forum meeting in Davos, Switzerland. This austere body of world leaders in business and politics identified 5 "X-factor" risks that face humanity in the foreseeable future. Amongst these is the discovery of extraterrestrial life which is reckoned to be a "game changer" with profound implications for mankind. As mentioned in this article the actual evidence is already well in place and what remains is merely a socio-political switch which has been resisted for too long. Humanity's self-image as a supreme life form is likely to be the first victim of the transformation that would require major efforts in psychological and educational readjustments. It is likely that the entire structure of modern society will undergo a transformation more fundamental and far-reaching than that which took place following the industrial revolution of the nineteenth century. A new age of colonisation might be contemplated when humans would attempt to establish colonies on other solar system bodies, or even on a planet orbiting a nearby star. Such endeavours would require major readjustments of priorities in science funding and resource allocation more generally. If the transforming discovery goes beyond discovering microbial life to include intelligent life in our vicinity the effect on the history of civilization will be impossible to predict.

\section{References}

1. Hoyle F, Wickramasinghe NC (1976) Primitive grain clumps and organic compounds in carbonaceous chondrites. Nature 264: 45-46.

2. Hoyle F, Wickramasinghe NC (1977a) Polysaccharides and the infrared spectra of galactic sources. Nature 268: 610-612.

3. Hoyle F, Wickramasinghe NC (1977b) Identification of the 2200A interstellar absorption feature. Nature 270: 323

4. Hoyle F, Wickramasinghe NC (1978) Lifecloud (J.M. Dent \& Sons, London).

5. Vanysek V, Wickramasinghe NC (1975) Formaldehyde polymers in comets Astrophysics and Space Science 33: L19-L28.

6. Hoyle F, Wickramasinghe NC (1981) Comets - a vehicle for Panspermia Comets and the Origin of Life 5:227-239.

7. Hoyle F, Wickramasinghe NC (1982 Proofs that Life is Cosmic, Mem. Inst Fund. Studies Sri Lanka.

8. Hoyle F, Wickramasinghe NC (1986) The case for life as a cosmic phenomenon Nature 322: 509-511.

9. Al-Mufti S (1982). PhD thesis, Cardiff University.

10. Hoyle F, Wickramasinghe NC (1991) The Theory of Cosmic Grains. Kluwer Academic Press, Dordrecht.

11. Hoyle F, Wickramasinghe NC (2000) Astronomical Origins of Life: Steps towards Panspermia. Kluwer Academic Press, Dordrecht.

12. Hoyle F (1994) Home is where the wind blows. University Books, USA.

13. Hoyle F, Wickramasinghe NC, Al-Mufti S (1984) The spectroscopic identification of interstellar grains. Astrophys. Sp Sci 98: 343-352.

14. Wickramasinghe NC (2012) DNA sequencing and predictions of the cosmic theory of life. Astrophys Space Sci.

15. Gibson $\mathrm{CH}$, Schild RE, Wickramasinghe NC (2011) The origin of life from primordial planets. Int J Astrobiol 10: 83-98. 
Citation: N Chandra Wickramasinghe, Tokoro G (2014) Life as a Cosmic Phenomenon: The Socio-Economic Control of a Scientific Paradigm. Astrobiol Outreach 2:113. doi: $10.4172 / 2332-2519.1000113$

16. Mayor M, Queloz D (1995) A Jupiter-mass companion to a solar-type star. Nature 378: 355-359.

17. Kopparapu $R$ (2013) A revised estimate of the occurrence rate of terrestrial planets in the habitable zones around kepler m-dwarfs.

18. Mojzsis SJ, Arrhenius G, McKeegan KD, Harrison TM, Nutman AP, et al. (1996) Evidence for life on Earth before 3,800 million years ago. Nature 384: 55-59.

19. Wickramasinghe $C(2010)$ The astrobiological case for our cosmic ancestry. International Journal of Astrobiology 9: 119-129.

20. Wickramasinghe C (2011) Bacterial morphologies supporting cometary panspermia: a reappraisal. International Journal of Astrobiology 10: 25-30.

21. Harris MJ, Wickramasinghe NC, Lloyd D, Narlikar JV, Hoyle F, et al. (2002) Detection of living cells in stratospheric samples.

22. Shivaji S, Chaturvedi P, Begum Z, Pindi PK, Manorama R, et al. (2009) Janibacter hoylei sp. nov., Bacillus isronensis sp. nov. and Bacillus aryabhattai sp. nov., isolated from cryotubes used for collecting air from the upper atmosphere. International Journal of Systematic and Evolutionary Microbiology 59: 2977-2986.

23. Hoyle F, Wickramasinghe C (1980) Evolution from Space.

24. Claus G, Nagy B (1961) A microbiological examination of some carbonaceous chondrites. Nature 192: 594-596.

25. Pflug HD (1984) Fundamental Studies and the Future of Science. Cardiff Press, UK.
26. Hoover RB (2005) Perspectives in Astrobiology. IOS Press, Greece.

27. Hoover RB (2011) Fossils of cyanobacteria in Cll carbonaceous meteorites Journal of Cosmology 13.

28. Wickramasinghe NC, Wallis J, Wallis DH, Schild RE, Gibson CH (2012) Lifebearing primordial planets in the solar vicinity. Astrophys Space Sci 341: 295299.

29. Wallis J, Miyake N, Hoover RB, Andrew O, Daryl HW, et al. (2013) The Polonnaruwa meteorite: oxygen isotope, crystalline and viological composition. Journal of Cosmology 21.

30. Wainwright M, Rose CE, Baker AJ, Briston KJ, Wickramasinghe NC (2013a) Isolation of a diatom frustules from the lower stratosphere $(22-27 \mathrm{~km})$. Journal of Cosmology 22: 10183-10188.

31. Wainwright M, Rose CE, Baker AJ, Wickramasinghe NC (2013b) Isolation of biological entities from the stratosphere $(22-27 \mathrm{~km})$. Journal of Cosmology 22 : 10189-10197.

32. Wainwright M, Rose CE, Baker AJ, Karolla R, Wickramasinghe NC (2013c) Biology associated with a titanium sphere isolated from the stratosphere. Journal of Cosmology 23: 11117-11124.

33. Schmitt-Kopplin P, Zelimir G, Régis DG, Agnes F, Basem K, et al. (2010) High molecular weight diversity in the extraterrestrial organic matter in the Murchison Meteorite, revealed 40 years after its fall. PNAS 107: 2763-2768 